\title{
Homenaje al Dr. Matías Pandolfi
}

Dra. Carmen Viera.

Profesora Entomología, Facultad de Ciencias, Universidad de la República. Jefa de Ecología del Comportamiento, IIBCE. MEC. cviera@fcien.edu.uy

El día 1 de marzo del 2021 falleció el Dr. Matías Pandolfi, Investigador Independiente del CONICET y profesor de la Facultad de Ciencias Exactas y Naturales de la UBA.

Sus colegas argentinos lo han homenajeado como merecía. https://www.conicet.gov.ar/el-conicet-lamentael-fallecimiento-de-matias-pandolfi/ss https://www. facebook.com/watch/?v=225110108669633

Sus vínculos con investigadores y docentes uruguayos ameritan nuestro pequeño aporte a su recordatorio.

Matías además de sus aportes científicos sobre la fisiología y comportamiento, fue un entusiasta docente y divulgador. Sus colegas han sintetizado sus méritos y reconocimientos académicos en redes y publicaciones, que son muy importantes, pero en esta instancia quiero recordar a Matías en toda su dimensión humana. Escritor de ciencia y de ficción, incansable, curioso, políticamente incorrecto, rara virtud en estos días, Matías supo generar vínculos humanos, más allá de los profesionales. Fue un hombre comprometido con la sociedad, defendiendo recursos para la ciencia, estimulando vocaciones y tendiendo puentes permanentemente. Tuvo vínculos internacionales con investigadores de renombre, incluyendo a investigadores de
Uruguay. Conmigo se relacionó desde mi posición de docente de comportamiento, invitándome a participar de un prestigioso curso de posgrado bianual que se dictaba en verano en la Universidad de Buenos Aires y contaba con una afluencia enorme de estudiantes de la región. Fue un excelente docente y comunicador, preocupado por su país y la integración de la región. Utilizó a la ciencia como una herramienta no solo de generar conocimiento, sino también como una fuente inagotable de independencia y valorización de la cultura en la región. Tuvimos la suerte de contar con su participación en el Comité Organizador de la II Reunión de Biología del Comportamiento Animal, en Montevideo, en diciembre de 2019.

Como divulgador, tuvo múltiples intervenciones en los medios masivos, https://twitter.com/MatiasPandolfi/ status/1346256779164921856

Participó en el Gato y la Caja, https://elgatoylacaja. com/author/pandolfi

Fue un ser humano noble, generoso, desinteresado, incansable activista de los derechos humanos y de la conservación de flora y fauna. A quienes tuvimos la suerte de conocerlo, su desaparición tan temprana, ya que no llegó a cumplir 40 años, nos deja un gran vacío. 